QUestão NuClear

\section{Matriz energética diversificada é opção mais segura para o país}

A discussão no Brasil e no mundo sobre gerar energia elétrica por usinas nucleares aumentou desde o terremoto seguido de um tsunami, ocorrido no nordeste do Japão em 11 de março último. Este sismo, de 8,9 pontos na escala Richter e seguido de inúmeras réplicas, afetou seriamente o Complexo Nuclear de Fukushima, que abrange seis reatores da Usina de Fukushima Daiichi e quatro reatores da Usina de Fukushima Daini, administrados pela Tokyo Electric Power Company (Tepco). Províncias como Morioka Miyagi, Iwate, Ibaragi e Fukushima foram devastadas; as duas últimas estão entre as mais afetadas pela radiação, segundo relatórios de situação da Organização Mundial de Saúde (OMS). Em 30 de março, a Agência Internacional de Energia Atômica (Aiea) recomendou ampliar a área de segurança de 30 para 40 quilômetros em torno do complexo nuclear e evacuar os 7 mil moradores da cidade de Iwate por causa do risco de contaminação radioativa.

Cada forma de geração tem vantagens e desvantagens. Mas é a energia nuclear a que desperta um sentimento mais forte de insegurança na sociedade. No imaginário de muita gente, energia nuclear é quase um sinônimo de acidente, como os das usinas nucleares de Three Mile Island e Chernobyl e com o Césio-137, ocorrido em Goiânia, em setembro de 1987. Desses três exemplos, apenas em Chernobyl se comprovaram mortes diretamente ligadas à usina nuclear, muitos casos de câncer e três países (Bielorússia, Federação Russa e Ucrânia) possuem territórios ainda afetados pela contaminação radioativa. Em Three Mile Island não foram registradas mortes, mas houve evacuação em massa da população local. Em Goiânia, o material radioativo foi retirado por catadores de ferro velho de um aparelho utilizado em radioterapia, que se encontrava em um hospital abandonado. Um total de 112,8 mil pessoas foram expostas aos efeitos do Césio-137, das quais 129 apresentaram contaminação corporal, 21 passaram por tratamento intensivo, das quais quatro morreram. Existem inúmeros processos para geração de energia elétrica, todos baseados no princípio da conversão de formas de energia. Pode ser feita a partir da transformação de energia cinética em elétrica, utilizando água (hidrelétrica) ou vento (eólica). Ou pode-se transformar energia térmica em elétrica, utilizando combustíveis fósseis (carvão mineral ou derivados do petróleo como óleo ou gás natural), elementos radioativos (urânio, tório, plutônio) e biomassa (madeira, bagaço de cana de açúcar e outros).
Atualmente, cresce também o uso da chamada energia fotovoltaica, na qual células solares, fabricadas à base de silício, convertem luz solar em eletricidade.

A aplicação de maior vulto da energia nuclear é, sem dúvida, para produção de energia elétrica. A cada dia, novas técnicas nucleares são desenvolvidas. As áreas mais beneficiadas são a medicina, na radioterapia; a agricultura, onde a irradiação é usada para conservação de alimentos; a indústria, particularmente a farmacêutica e a metalúrgica; e na pesquisa científica, no uso de traçadores radioativos e de Carbono-14 para datação.

RISCOS SEMPRE PRESENTES Para José Eduardo Martinho Hornos, professor do Instituto de Física de São Carlos (IFSC) da Universidade de São Paulo (USP), riscos no uso da energia nuclear existem sempre e os prejuízos ambientais e humanos já registrados foram significativos. "Mas esses prejuízos foram menores do que se alardeou em Chernobyl, hoje um parque ecológico; foram mínimos em Three Miles Island; e comparativamente pequenos com relação ao Japão", diz Hornos que, como doutor em física nuclear, considera que "se deve explorar todas as formas de energia e para cada situação existe uma solução energética apropriada”.

Em sua dissertação de mestrado, defendida em 2007 no Instituto de 


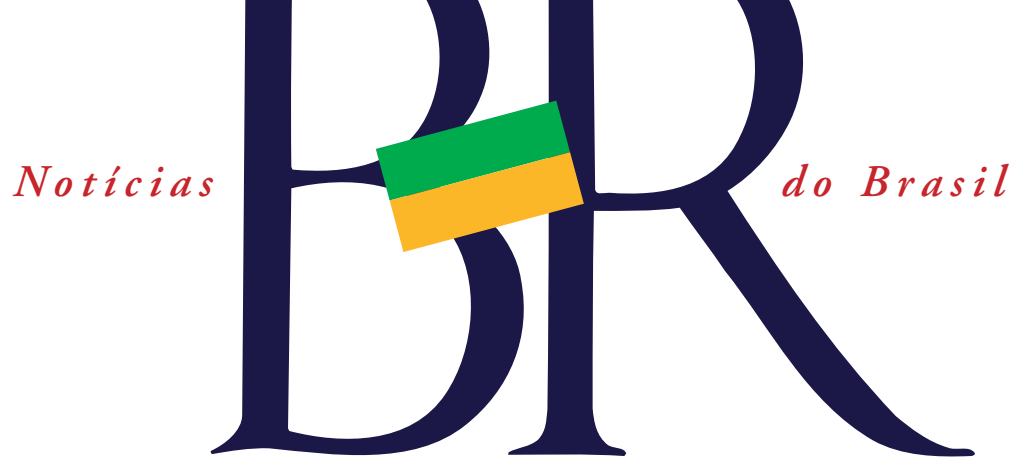

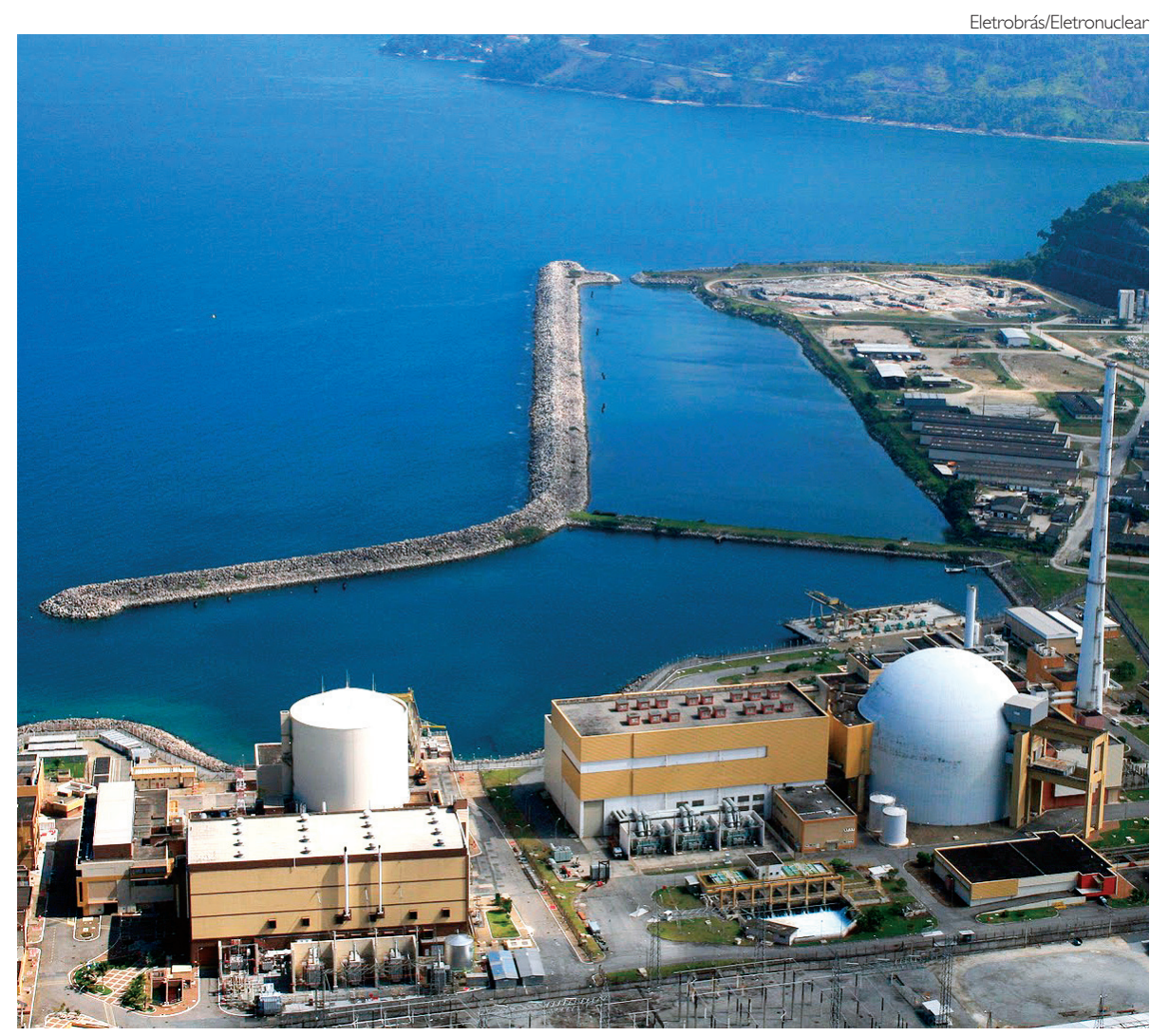

Brasil possui 2 usinas nucleares em operação em Angra dos Reis (RJ), enquanto EUA possuem 104 e França 59, segundo dados da IAEA de 2009

Pesquisas Energéticas e Nucleares da USP, a engenheira civil Ana Maria de Oliveira Guena mostra que cada sistema gerador de eletricidade gera impactos que envolvem: o uso da terra na obtenção/extração, processamento e conversão do combustível em eletricidade; a poluição do ar, do solo e das águas associadas à conversão; a emissão de radiação e/ou poluentes durante a operação normal ou em caso de acidente; os fatores de saúde ocupacional associados a cada etapa; o armazenamento dos resíduos sólidos; e os riscos inerentes à desativação das respectivas unidades geradoras de energia. Ela analisou cinco formas de geração de energia elétrica (termelétrica, nuclear, hidrelétrica, eólica e solar) e seus impactos ambientais, e concluiu que a geração nuclear oferece $o$ maior rendimento, mas ressalta que a desativação de uma usina nuclear exige isolamento total da central, com vigilância e monitoramento durante 24 horas por dia, durante todo o período que o material usado na geração de energia levar para decair a níveis não comprometedores para o ambiente, o que pode durar mais de 100 anos.

É no quesito riscos de acidentes que o uso de energia nuclear provoca maiores incertezas, e a impossibilidade de quantificar todos os seus efeitos ambientais, deixam dúvidas quanto a pertinência de se priorizar investimentos em usinas nucleares, particularmente em países que possuem outras alternativas.

$\mathrm{Na}$ matriz energética japonesa, $29 \%$ da energia elétrica provêm de 54 usinas nucleares. Atualmente, 30 países possuem usinas nucleares em operação, dos quais 10 detêm mais de $80 \%$ do total de $437 \mathrm{em}$ funcionamento. No Brasil, 77\% da energia elétrica provêm de usinas hidrelétricas e apenas 2,6\% são gerados pelas nossas duas usinas nucleares (Gráfico 1).

USINA DE ANGRA 3 EM 2015 No Plano Decenal de Expansão de Energia 2019 (PDE 2019), publicado pelo Ministério de Minas e Energia (MME) e pela Empresa de Pesquisa Energética (EPE), está prevista a implantação em junho de 2015 da usina de Angra 3, com 1.405 megawatts (MW), o que representará um aumento de $70 \%$ do parque nuclear atualmente existente. Para o físico nuclear José Goldemberg, co-presidente do Global Energy Assessment, sediado em Viena, "quando 
Gráfico 1 - Oferta interna de elétrica no Brasil

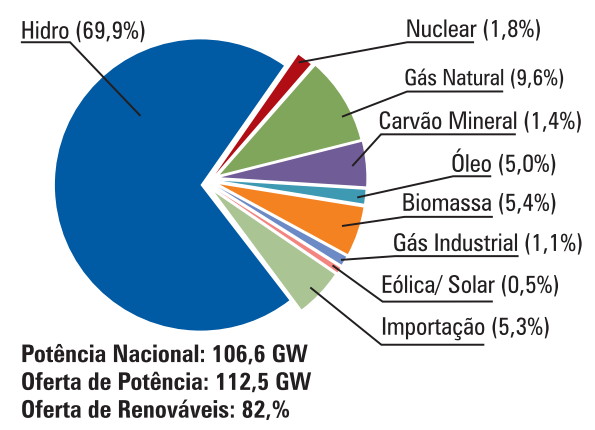

Fonte: Resenha Energética 2009 Preliminar. Disponível em: http://www. mme.gov.br/mme/galerias/arquivos/ publicacoes/BEN/3_-_Resenha_ Energetica/Resenhä_Énergetica_2009_-PRELIMINAR.pdf. Consultado em 30/3/2011.

Angra 3 ficar pronta, a energia gerada será menor que o potencial de produção de energia do bagaço de cana, que só em São Paulo é de 2 MW". Em entrevista à Exame.com em 17 de março último, Goldemberg, eleito pela revista Times um dos Heróis do Meio Ambiente, em 2007, considera a energia nuclear dispensável no Brasil: "Não precisamos disso. Apesar de atraente, esse tipo de geração deve ser a última das opções, restrita a países que não têm outra opção, como a França”.

DIVERSIFICAR É A MELHOR OPÇÃO A analista ambiental Ana Maria Dolabella, com base em sua experiência à frente da Diretoria de Licenciamento e Avaliação Ambiental do Ministério do Meio Ambiente (MMA), insiste na importância da diversificação da matriz energética brasileira. Ela destaca a importância da energia de biomassa e salienta que não devemos pensar apenas em bagaço de cana de açúcar: "Em 2010, fizemos uma pesquisa para subsidiar os processos de licenciamento ambiental de empreendimentos de geração de energia elétrica por biomassa, e amostramos 94\% dos empreendimentos em operação no Brasil. Nesse estudo, constatou-se que estão sendo usados, além do bagaço de cana, resíduo de madeira, licor negro (ou lixívia, rejeito tóxico das indústrias de papel e celulose), casca de arroz, capim elefante, resíduo sólido urbano, excrementos de animais, entre outros resíduos".

Dados disponíveis no Banco de Informaçōes de Geração da Agência Nacional de Energia Elétrica (Aneel) mostram existir hoje no Brasil 400 empreendimentos de geração de energia elétrica por biomassa, responsáveis pela produção de 7.986,9 MW de potência que representam $6,5 \%$ da matriz energética brasileira. Ana Dolabella acrescenta que, embora a cana represente quase $80 \%$ da energia gerada por biomassa, o resíduo de madeira vem crescendo de importância e se estima um potencial de 1.300 MW dessa fonte que poderiam ser aproveitados no Brasil. Para a bióloga Vania Soares, que possui mestrado em ecologia, não existe um modelo de produção de energia que seja 100\% limpo e seguro. As pequenas centrais hidrelétricas (PCH), por exemplo, que produzem até 30 MW, são instaladas principalmente em rios de pequeno e médio portes que possuem desníveis significativos durante seu percurso, para gerar potência hidráulica suficiente para movimentar as turbinas. No conjunto, explica Vania, as PCH geram menor impacto ambiental, mas localmente podem causar fragmentação de rios. Já as termelétricas são uma opção como backup. "Nos períodos de menor oferta pluviométrica, termelétricas que usam biomassa, reaproveitando resíduos, podem ser opções para pequenas comunidades", acrescenta. Em sintonia com o MME, Ana e Vania defendem a diversificação da matriz energética brasileira, mas sem a ampliação do uso da energia nuclear, devido ao tamanho e à imprevisibilidade dos riscos. Não são as únicas a pensarem dessa forma. Hirose Takashi, escritor japonês que tem criticado duramente as ações da Tepco em Fukushima, em seu livro Nuclear power plants for Tokyo questiona: "se os defensores da ideia [de geração de energia elétrica por usinas nucleares] têm tanta certeza que as centrais nucleares são seguras, porque não construí-las no centro da cidade em vez de a centenas de quilômetros, quando se perde metade da energia pelos cabos condutores?”.

Leonor Assad 